\title{
Output taxation, human capital and growth
}

\author{
Rosa Capolupo* \\ Dipartimento di Scienze Economiche \\ Università di Bari \\ Via Camillo Rosalba 53 \\ 70124 Bari (Italy) \\ tel. $++39+80 / 5049039$ \\ e-mail:capolupo@tno.it
}

\begin{abstract}
This paper investigates the long run effects of government spending and taxation in an endogenous growth setting. The model is a variant of Barro's (1990) and Lucas' (1988) models in which human capital accumulation is driven by government spending on public education. To balance the budget the government levies a tax on output in two alternative specifications for the human capital accumulation equation. The results consolidate some recent findings that taxation, when it is used for productive purposes, may lead to faster growth. Growth rates increase in taxes up to a level around $60-70 \%$
\end{abstract}

Keywords: growth, taxation, human capital JEL classification numbers: O40, O38, H52, F21,

*I wish to thank Anton Muscatelli for helpful conversations and comments. I, alone, am responsible for opinions and any errors in this paper. The paper is part of a research program supported by MURST $40 \%$ funds. 


\section{Introduction}

The resurgence of interest in the dynamic effects of fiscal policy is documented by the extensive literature on this topic both for exogenous (Chamley [1986], Judd [1986], Auerbach and Kotlikoff [1987]) and endogenous models of growth. While in the exogenous growth theories the growth rate is determined by exogenous factors and tax rates affect only the long run level of per capita income, a crucial question in the new theories of growth concerns the effects of fiscal policy on the economy growth rate.

Indeed, in an endogenous growth setting the effects of taxation on growth have been investigated by many authors from both positive and normative perspectives. Although the quantitative growth effects differ considerably, all these studies share the common conclusion that taxation is growth reducing. Hence, the results of these researches parallel the common wisdom that taxes have distortionary effects on growth. Therefore, they should be low in the long run, approaching zero in an optimal Ramsey setting ${ }^{1}$. King and Rebelo (1990) and Rebelo (1991), who initiated the more recent literature on this topic, have investigated the effects of taxation on growth in both neoclassical and endogenous growth models and they found that long run growth is seriously distorted in models where it is endogenously determined. Lucas (1990), who examined growth and the welfare effects from taxes in endogenous growth models with human capital, found small negative effects. One of Lucas' (1990) conclusions, however, is that in models in which taxation is used to supply education or public health, the conventional result might be reversed, but the author did not explore this case formally ${ }^{2}$.

Whatever the theoretical argument in favour of low or zero taxation (either on output, consumption, labour, or capital incomes) this argument is not convincingly supported by empirical findings, using aggregate data. Empirical studies show no negative correlation between government spending and taxation with growth ( Ram Rati [1986], Easterly and Rebelo [1994] among others).

We examine in this paper the impact on growth of a tax on output in a model in which growth is driven by human capital accumulation through public education. Such a tax, under constant return to scale technology, is equivalent to an income tax on both physical and human capital earnings. (see King ad Rebelo [1990]). The analysis is carried out in the context of a representative agent framework and therefore we disregard redistributive issues of fiscal policy.

Our set-up is substantially similar to Barro's (1990)-Lucas' (1988) models without an endogenous labour-leisure choice. Labour supply is fixed and we assume

\footnotetext{
${ }^{1}$ Initial seminal contributions on optimal taxation are those by Chamley (1986), and Judd (1986). Both authors showed that optimal taxation in an exogenous growth model should be zero in the long run. However, the labour income tax could be positive given that the time endowment (labour/leisure) is also in fixed supply in the long run. So the conclusion was that the capital income tax should be zero while labour income can be taxed. For different results in the endogenous growth setting see Roubini and Milesi Ferretti (1994)

${ }^{2}$ Other more recent papers by Milesi Ferretti and Roubini (1994, 1995), Pecorino (1993), Devereux and Love (1994) found large distortions from taxation on economic growth. By contrast Jones Manuelli ad Rossi (1993), Devereux and Love (1995), Capolupo (1996) Corsetti and Roubini (1996), Turnovsky (1996), Uligh and Yanagawa (1996), open the possibility of positive effects, depending on the model structure and the tax schemes adopted. A synthesis of some of these studies are discussed by Stokey and Rebelo (1995).
} 
that the tax is levied in order to provide education. The tax experiment that we will perform is closely related to King and Rebelo's (1992) work. The paper shows that a higher income tax leads to faster growth. The main finding is that increasing the output tax from 10 to 60 percent would increase the growth rate under plausible parameterizations. For marginal tax rates which are higher than $60 \%$, the distortionary impact becomes evident and the growth rate will decrease.

These results are not surprising. It is worth noticing that it is common in this literature to assume that the proceeds of tax revenues are rebated in lump sum fashion to agents in the economy. This assumption enables one to separate out the pure distortionary effect of the tax from the expenditure effects. But, if tax revenues are used to finance utility or productivity augmenting government expenditures, the general conclusions about the impact of taxation on growth can be overturned.

The remainder of this paper is organised as follows. Section 2 presents a model in which public schooling is the only input in the human capital accumulation equation. After having solved for the steady state value of the growth rate, we carry out an experiment simulating an increase of the tax rate on output and the effects on growth are computed. In section 3 we extend the first model by adding private inputs in the process of human capital accumulation. The explicit numerical solution of this model is performed and the discussion of the results are presented in section 4. The paper concludes with section 5 .

\section{A tax on output and its impact on growth}

\subsection{A Model with public goods as the only input in the human capital production function}

A basic endogenous growth model is presented. The feature of the model has been kept very simple to focus on taxation and expenditure issues. There is only one production sector, which is characterized by perfect competition, producing only one good in the economy. This commodity can be used for consumption or capital investment and its price is normalized to unity. The output $\mathrm{Y}$ is produced by means of physical and human capital according to a constant returns Cobb-Douglas production function:

$$
Y(t)=K(t)^{\alpha} H(t)^{1-\alpha}
$$

where $\alpha$ is the capital share, and $\mathrm{H}$ the amount of human capital incorporated in people which are assumed to be equal to one (no population growth). The other symbol $\mathrm{K}$ is the amount of physical capital. The economy is assumed to be populated by a large number of identical individuals who maximise a constant intertemporal elasticity of substitution utility function over an infinite horizon:

$$
U=\int_{0}^{\infty} e^{-\rho t} \frac{(C)^{1-\sigma}-1}{1-\sigma} d t
$$

where $e^{-\rho t}$ reflects discounting of future consumption ( $\rho$ being the constant subjective rate of time preference) and $\sigma$ is the coefficient of risk aversion or the inverse of the elasticity of intertemporal substitution. We assume that $\sigma$ is equal to unity, so the 
lifetime utility function becomes logarithmic. Except where necessary, time subscripts have been dropped from the notation.

The other feature of the model is the provision of education by the government which determines the accumulation of human capital through full time public schooling:

$\dot{H}=B G$

where $\mathrm{G}$ is government expenditure (public provided goods) and $\mathrm{B}$ is a productivity parameter as in Lucas (1988). It is important to notice that in this model (the assumption is dropped in the next model) consumption, physical and human capital are perfect substitutes since human capital is produced and accumulated using revenues from the taxation of private production.

The model treats education as provided solely by the government. This is a modelling assumption, even though it is a very close formulation of the way human capital is accumulated in most of the countries through formal schooling. We rule out deficit financing, so that the government levies a tax on output to balance the budget:

$G=\tau Y$

where $\tau$ is the proportional tax on the aggregate of gross output. The economy resource constraint is:

$C(t)+G(t)+\dot{K}(\dot{t})=Y(t)=K^{\alpha} H^{1-\alpha}$

The equation for physical capital accumulation, taking account of taxation is:

$\dot{K}=(1-\tau) K^{\alpha} H^{1-\alpha}-C$

Given the one sector nature of the model, the only constraint that the household must take into account in maximising the lifetime utility function is equation (5). The representative agent takes $\mathrm{G}$ as given and this means that human capital is also exogenous to him. The problem is to choose $\mathrm{C}$ and investment to maximise the utility function that, rewritten in $\log$ form, is:

$\operatorname{Max} U=\int_{0}^{\infty} \log (c) e^{-\rho t} \mathrm{dt}$

Since there is only one state variable $\mathrm{K}$ and one control variable $\mathrm{C}$ the Hamiltonian for this problem is :

$H=\log (C) e^{-\rho t}+\lambda\left[(1-\tau) K^{\alpha} H^{1-\alpha}-C\right]$

where $\lambda(t)$ is the costate variable that is the present value shadow price of $K(t)$. Combining first order conditions we get the formula for the growth rate of consumption:

$\gamma_{C} \equiv \frac{\dot{C}}{C}=\left[\alpha(1-\tau)(K / H)^{\alpha-1}-\rho\right]$ 
We solve the model for the balanced growth path along which the growth rates of output, physical capital and human capital are all equal. This entails that:

$\gamma \equiv \dot{H} / H=B \tau(K / H)^{\alpha} \Rightarrow(K / H)=\left[\frac{\gamma}{B \tau}\right]^{1 / \alpha}$

and substituting this value for $\mathrm{K} / \mathrm{H}$ in equation (7) we get:

$\gamma=\left[\alpha(1-\tau)\left(\frac{\gamma}{B \tau}\right)^{\frac{\alpha-1}{\alpha}}-\rho\right]$

Equation (8) shows that the tax rate acts on the growth rate in two opposite directions. The term (1- $\tau)$ represents the negative effect of taxation on output while the term $B \tau$ represents the positive effect of public education on human capital accumulation. An increase in $\tau$ reduces the ratio $\mathrm{K} / \mathrm{H}$ and therefore increases the marginal productivity of physical capital. Since from the above equation the net impact of taxation on output is not clear, we shall compute some numerical simulations. We will show that the positive effect dominates and hence $\gamma$ rises with $\tau$.

\subsection{Numerical solution and taxation experiments of the model}

For the parameters of the model we shall use some values suggested by the econometric literature and perform the experiment of changing the output tax rate in order to evaluate its effects on the growth rate as well as on the physical to human capital ratio. An increase in the tax rate yields a new steady state value for the growth rate and for the value of the physical to human capital ratio which is distorted by taxation. As there is no endogenous leisure choice in this model, there is no distortion in the choice of agents between leisure and work hours.

\subsection{Parameters}

To carry out our simulations, a number of parameter values are needed, in addition to the values of the tax rate. The set of parameters chosen are those used in similar work in this field. The model does not require specific values for the elasticity of substitution between present and future consumption because of the assumption of $\log$ preferences. In any case, assuming values of $\sigma$ lower than one and very close to the value estimated by some authors (see for example Hall, 1988) does not alter the results. Following the practice of other studies, we assume that the capital share is 0.35 which corresponds to the capital share for several Western countries ${ }^{3}$. The results are fairly robust even if we change this value (see the sensitivity analysis). The parameter for the rate of time preference $\rho$ is assumed to be equal to 0.04 . The conventional range for this parameter is $0.02-0.04$ and its value is related to the real rate of return on equity for the US post-war period. In the sensitivity analysis we take account also of the possibility of a lower value of $\rho$ as in Barro and Sala-i Martin (1992) who use a value of $\rho$ equal to 0.02 . To calibrate the model, we choose a value for the

${ }^{3}$ Obviously 0.65 is the estimate for human capital share in many studies, see for example Devereux and Love (1994, 1995) and Pecorino (1993) 
productivity parameter B for the base case, so that with a tax rate on output of $20 \%$ the aggregate growth rate is close to the average growth rate of the majority of OECD countries in this century (roughly equal to $2.8 \%$ according to Maddison's [1991] estimates)

\subsection{Results}

In contrast with the experiments of a Ramsey-type ${ }^{4}$ which involve calibrating the model, fixing a tax rate which gives a value of the steady state growth rate approximately equal to the average growth rate for industrialised countries, and then decreasing the tax rate to zero, or near zero in order to evaluate the impact of taxation, our experiment points in the other direction. It involves increasing the tax rate from 10 to $100 \%$ and evaluating the impact on the steady state growth rate. The values for the steady state growth rates are reported in Table 1

\section{TABLE 1}

Parameter values for the benchmark case: $\{B=0.08, \alpha=0.35, \rho=0.04\}$ :

VALUES OF THE STEADY STATE GROWTH RATES

\begin{tabular}{|c|c|c|c|}
\hline Tax rate $\tau$ & Growth rate $\gamma$ & $\begin{array}{c}\text { Percentage change in } \\
\text { growth rate } \Delta \gamma\end{array}$ & Factors ratio $\mathrm{K} / \mathrm{H}$ \\
\hline 0.10 & 0.01593 & & 1.2112 \\
\hline 0.15 & 0.02237 & 0.64 & 1.8648 \\
\hline 0.20 & 0.02811 & 0.57 & 1.7573 \\
\hline 0.25 & 0.03327 & 0.51 & 1.6635 \\
\hline 0.30 & 0.03790 & 0.46 & 1.5793 \\
\hline 0.35 & 0.04205 & 0.41 & 1.5019 \\
\hline 0.40 & 0.04574 & 0.37 & 1.4294 \\
\hline 0.45 & 0.04897 & 0.32 & 1.3604 \\
\hline 0.50 & 0.05175 & 0.28 & 1.2937 \\
\hline 0.55 & 0.05404 & 0.23 & 1.2283 \\
\hline 0.60 & 0.05583 & 0.18 & 1.1632 \\
\hline 0.65 & 0.05705 & 0.12 & 1.0973 \\
\hline 0.70 & 0.05764 & 0.06 & 1.02939 \\
\hline 0.75 & 0.05747 & -0.017 & 0.9579 \\
\hline 0.80 & 0.05634 & -0.113 & 0.8804 \\
\hline
\end{tabular}

Note: The values for the growth rates have been computed also for tax rates from 80 to 100 percent. Although these values are not reported in the table, they are plotted in Figure 1. As it is possible to see in this model, the growth rate is positive but decreasing for tax rates in the range between 70 to $100 \%$

The values that appear in the Table show that the growth rate is increasing in the tax rate and the tax rate that maximises growth is approximately equal to $72 \%$. From the table it is possible to show that an increase in the tax rate from 10 to $20 \%$ raises the growth rate by 1.2 percentage points. If we increase the tax rate from 20 to $30 \%$ the growth rate increases by 0.9 percentage points. In Figure 1 we plot growth rates against tax rates.

\footnotetext{
${ }^{4}$ For a discussion and a demonstration of how these experiments are conducted see Roubini and Milesi-Ferretti (1994). The authors make use of the Ramsey method but follow the Lucas and Stokey procedure.
} 


\section{( Figure 1)}

The concavity of the function depicted in Fig 1 is very similar to other important findings in the theory of public finance, such as the Laffer curve, as well as the Barro model of public spending and endogenous growth. The first important prediction of the Barro model is that growth is a non-monotonic function of government size which implies a trade off between government size and growth. The novelty here is that we do not have a hump-shaped curve, therefore the growth rate never becomes zero or negative even if it is decreasing for very high tax rates (more than 70\%). The reason is that the tax rate used to provide direct education by the government has a more powerful effect on growth rates than indirect services to production as in Barro (1990).

\section{(Figure 2)}

In figure 2 we plot the steady-state values for the physical to human capital ratio. The increase in human capital makes this ratio decrease as expected. The effects of a decreasing factor ratio on growth are well described in Mulligan and Sala-i-Martin's (1993) paper. We can expect that during the transition to the steady state the higher the amount of human capital the more the ratio is far below its steady state value. This contributes to faster growth in terms of transitional dynamics.

To test the robustness of the model to our parameter choices we replicated the simulations with different values of $B, \alpha$ and $\rho$. What this sensitivity analysis shows is that changes in these parameters do not change the relationship between taxation and growth, which remains positive for high tax rates. The growth rate which maximises growth is always in the range $0.60-0.70$. Obviously the growth rate is sensitive to the value of B, the productivity parameter. According to Lucas (1988) and Uzawa (1965) the long run growth depends on both time spent on acquisition of skills, which in this model is decided by the government, and the effectiveness with which these new skills are acquired. With a value of $B$ equal to 1 and a tax rate of 10 percent the growth rate would be, ceteris paribus, equal to $12 \%$ and a change in the tax rate from 10 to 20 percent increases the growth rate by $8 \%$ (not reported in tables). Hence, the higher the total productivity in the human capital sector the larger the effect on growth.

In the sensitivity analysis we perform calculations of the growth rates for different values of $\alpha$. With a lower value of $\alpha$ with respect to the base case the effects on growth are, as expected, relatively smaller but they remain positive as the values for the growth rates reported in the table show. Because in the debate on growth it has been argued that an upper bound for the share of physical capital would be about 0.50 we use this value in our sensitivity analysis. Qualitatively the results do not change even though, as before, a higher share of physical capital means higher output and therefore higher tax revenues and human capital accumulation, making the impact of taxation on growth stronger. Changing in the value of $\rho$ does not change the main result. It is not a critical parameter and its effects are those described by the formula on growth rate as the values displayed in table 2 show. 
TABLE 2

SENSITIVITY ANALYSIS: PERCENTAGE DIFFERENCES OF GROWTH RATES WITH RESPECT TO THE BASE CASE

\begin{tabular}{cccccc} 
tax rate $\tau$ & $\mathrm{B}=0.2$ & $\mathrm{~B}=0.5$ & $\alpha=0.25$ & $\alpha=0.50$ & $\rho=0.02$ \\
\hline 0.10 & +1.94 & +4.33 & -0.41 & +1.2 & +0.25 \\
0,15 & +2.62 & +6.08 & -0.53 & +1.5 & +0.30 \\
0.20 & +3.21 & +7.68 & -0.62 & +1.7 & +0.35 \\
0.25 & +3.73 & +9.17 & -0.73 & +1.8 & +0.36 \\
0.30 & +4.19 & +10.6 & -0.76 & +1.9 & +0.37 \\
0.35 & +4.59 & +11.8 & -0.77 & +1.88 & +0.38 \\
0.40 & +4.95 & +14.2 & -0.76 & +1.84 & +0.39 \\
0.45 & $+5,26$ & +15.2 & -0.73 & +1.65 & +0.40 \\
0.50 & +5.53 & +16.2 & -0.69 & +1.52 & +0.41 \\
0.55 & +5.76 & +17.0 & -0.64 & +1.35 & +0.41 \\
0.60 & +5.93 & +17.3 & -0.57 & +1.15 & +0.41 \\
0.65 & +6.17 & +17.02 & -0.47 & +0.9 & +0.41 \\
0.70 & +6.10 & +16.3 & -0.38 & +0.6 & +0.42 \\
0.75 & +6.09 & +16.1 & -0.36 & +0.41 \\
0.80 & +5.98 & + & +0.40 \\
\hline
\end{tabular}

Note: the steady-state growth rates reported in this table are a consequence of parametric changes in $B, \alpha$ and $\rho$. These values need to be compared with the growth rate values reported in table 1 .

Each column reports the percentage change of the growth rate with respect to the base case for different values of the parameter indicated. The sensitivity analysis demonstrates that the results on the impact of taxation on growth rates are robust. There is no change in the pattern of growth up to the point where the tax rate becomes distorting.

\section{A tax on output in an endogenous growth model with public and private investment in human capital}

\subsection{The Model}

In this section we extend the model in such a way as to take into account not only compulsory public schooling but also the private choice to invest in human capital. Because education is not completely privately or publicly supplied, we use a function for the production of human capital in which both public goods and time enter as inputs. The technology that describes the production of human capital as in Glomm and Ravikumar (1992) is specified as a Cobb-Douglas:

$$
H=B G^{\beta}[(1-u) H]^{1-\beta}
$$

where $(1-\mathrm{u})$ is time devoted to human capital production while $\mathrm{u}$ is the fraction of time used for the production of consumables and investment goods. Hence, time endowment, net of leisure, is normalised to one.

Physical output is produced with a constant return to scale technology that uses physical as well as human capital: 
$Y=K^{\alpha}(u H)^{1-\alpha}$

The dynamic equation for the accumulation of human capital, considering that it depreciates at the rate $\delta$, equal by assumption to the depreciation rate of physical capital, is:

$\dot{H}=B G^{\beta}[(1-u) H]^{1-\beta}-\delta H$

The first part of the right hand side of the equation (11) stands for educational expenditure provided by the government. The second part corresponds to education privately acquired defined by the time devoted to this scope. It measures the schooling effort of agents to acquire skills as in Lucas (1988). As before, B is a productivity parameter and $\beta$ is the share of public expenditure in the educational sector. Hence 1- $\beta$ is the share of private investment in human capital production.

The equation for physical capital accumulation is given by:

$\dot{K}=Y-\delta K-C-G$

where $\mathrm{C}$ is private consumption and $\delta$ is the depreciation rate. Since we assume that the government finances public expenditure with a tax on output, the balanced fiscal budget is given by:

$G=\tau Y$

Substituting the value of $\mathrm{G}$ in the equation of accumulation of physical capital (equation 12), we get:

$\dot{K}=(1-\tau) K^{\alpha}(u H)^{1-\alpha}-C-\delta K$

Consumer's utility maximization is subject to the constraint on physical capital accumulation given by (14) and to the human capital accumulation equation given by (11) and the two transversality conditions:

$\lim _{t \rightarrow \infty} \lambda(t) K(t)=0$

$\lim _{t \rightarrow \infty} v(t) H(t)=0$

The Hamiltonian for this problem can be written as:

$$
H=\ln (C) e^{-\rho t}+\lambda\left[(1-\tau) K^{\alpha}(u H)^{1-\alpha}-C-\delta K\right]+v\left[B G^{\beta}((1-u) H)^{1-\beta}-\delta H\right]
$$

The first order conditions are:

$$
\begin{aligned}
& \partial \mathrm{H} / \partial C=0 \Rightarrow 1 / C e^{-\rho t}=\lambda \quad \cdots \quad(16.1) \\
& \partial H / \partial u=\lambda\left[(1-\tau) K^{\alpha}(1-\alpha) u^{-\alpha} H^{1-\alpha}\right]+v\left[-B G^{\beta}(1-\beta)(1-u)^{-\beta} H^{1-\beta}\right]=0 \quad(16.2) \\
& \dot{\lambda}=-\partial H / \partial K=-\lambda\left[(1-\tau) \alpha K^{\alpha-1} u^{1-\alpha} H^{-\alpha}-\delta\right] \quad(16.3) \\
& \left.\dot{v}=-\partial H / \partial H=-\lambda\left[(1-\tau) K^{\alpha} u^{1-\alpha} H^{-\alpha}(1-\alpha)\right)\right]-v\left[B G^{\beta}(1-u)^{1-\beta} H^{-\beta}(1-\beta)-\delta\right](16.4)
\end{aligned}
$$


Condition (16.1) implies:

$-\rho-\frac{\dot{C}}{C}=\frac{\dot{\lambda}}{\lambda}$

Condition (16.2) implies:

$\frac{\lambda}{v}=\frac{B G^{\beta}(1-\beta)(1-u)^{-\beta} H^{1-\beta}}{(1-\tau) K^{\alpha}(1-\alpha) u^{-\alpha} H^{1-\alpha}}$

Condition (16.3) implies:

$\frac{\dot{\lambda}}{\lambda}=-\left[(1-\tau) K^{\alpha-1} \alpha u^{1-\alpha} H^{1-\alpha}-\delta\right]$

Condition (16.4) implies:

$\frac{\dot{v}}{v}=-\left(\frac{\lambda}{v}\right)\left[(1-\tau) K^{\alpha} u^{1-\alpha} H^{-\alpha}(1-\alpha)\right]-\left[B G^{\beta}(1-u)^{1-\beta} H^{-\beta}(1-\beta)-\delta\right]$

From condition(16.2.1) substituting the value of $\lambda / v$ in (16.4.1) and simplifying yields:

$\frac{\dot{v}}{v}=-B G^{\beta}(1-\beta)(1-u)^{-\beta} H^{-\beta}+\delta$

To find the growth rate we combine(16.3.1) with (16.1.1) and get:

$\gamma_{C}=(1-\tau)\left[(K / H)^{\alpha-1} \alpha u^{1-\alpha}-\delta-\rho\right]$

For the growth rate of human capital taking equation (16.2.1) and differentiating with respect to time yields:

$\frac{\dot{\lambda}}{\lambda}-\frac{\dot{v}}{v}=\beta \frac{\dot{G}}{G}+(1-\beta) \frac{\dot{H}}{H}-\alpha \frac{\dot{K}}{K}-(1-\alpha) \frac{\dot{H}}{H}$

substituting for $\frac{\dot{G}}{G}=\frac{\dot{H}}{H}=\frac{\dot{K}}{K}$ as well as for the expressions of the growth rates of shadow prices of physical and human capital we get :

$\gamma_{H}=B G^{\beta}(1-\beta)(1-u)^{-\beta} H^{-\beta}-\delta-\rho$

To find the growth rates in terms of the parameters of the model we substitute $G=\tau \mathrm{Y}$ in the expressions for the growth rates of $\mathrm{K}, \mathrm{H}, \mathrm{v}$, and $\lambda$. The following equations are obtained: 
$\gamma_{K}=(1-\tau)\left(\frac{K}{H}\right)^{\alpha-1} u^{1-\alpha}-\frac{C}{K}-\delta$

$\gamma_{H}=B \tau\left[\left(\frac{K}{H}\right)^{\alpha} H\right]^{\beta}(1-u)^{1-\beta} H^{-\beta}-\delta$

$\gamma_{v}=-B \tau^{\beta}\left[\left(\frac{K}{H}\right)^{\alpha} H\right]^{1-\beta}(1-\beta)(1-u)^{-\beta} H^{-\beta}+\delta$

$\gamma_{\lambda}=-(1-\tau) \alpha\left(\frac{K}{H}\right)^{\alpha-1} u^{1-\alpha}+\delta$

After having substituted in equations (20) and (21) the values of $\gamma_{\mathrm{v}}$ and $\gamma_{\lambda}=-\gamma-\rho$ from equations (16.1) the balanced growth equations (19)-(22) can be transformed, by defining $\mathrm{K} / \mathrm{H} \equiv \mathrm{k}$ and $\mathrm{C} / \mathrm{K} \equiv \mathrm{z}$, in the following way:

$\gamma_{K}=(1-\tau) K^{\alpha-1} u^{1-\alpha}-z-\delta$

$\gamma_{H}=B \tau^{\beta}\left(k^{\alpha} H\right)^{\beta}(1-u)^{1-\beta} H^{-\beta}-\delta$

$\gamma_{v}=-B \tau^{\beta}\left(k^{\alpha} H\right)^{1-\beta}(1-\beta)(1-u)^{-\beta} H^{-\beta}+\delta$

$\gamma_{\lambda}=-(1-\tau) \alpha k^{\alpha-1} u^{1-\alpha}+\delta$

These 4 equations determine the variables $\gamma, \mathrm{k}, \mathrm{z}$, and $\mathrm{H}$. It is not possible to derive a closed form solution to the system. However we may solve the equations (23)-(26) numerically for specific parameterizations. Then we compute the response of steady state growth rates and other variables to change in output taxation.

\subsection{Parameters}

The model is calibrated by the choice of $B$ in such a way that a balanced growth rate of $2.7 \%$ is obtained (the same steady state benchmark growth rate of the first model) under the assumption of $20 \%$ taxation. The choice of $20 \%$ taxation rate for the base case is the same fixed by King and Rebelo (1990). The value of B which gives this growth rate in this model is 0.38 .

For parameters which are common to both models, we use the same values as previously.

There are, however, a greater number of parameters because of the different technology in the production of human capital. Some difficulties arise in the choice of these parameters because of lack of empirical evidence concerning the nature of the human capital accumulation process. Crucial parameters are, indeed, those which 
characterize the coefficients of human capital production function. Which value should we assign to $\beta$, the share of government expenditure on education? In fixing it, we try to follow the few existing studies on this topic ${ }^{5}$. The value of the share of government spending on education has been estimated to be very high. If only high school and college education are counted, the factor share seems to be about $70 \%$ in the US (for a discussion of this value see Trostel [1993]). We assume as a base case a value of $\beta$ equal to 0.45 , and then we perform calculations for a higher value in the sensitivity analysis $(\beta=0.65)$. Another value to be fixed in this model is the depreciation rate for both physical and human capital. Also in the choice of this parameter we follow the main literature such as King and Rebelo (1990), Devereux and Love (1994) and others, in setting depreciation rates for both factors equal to 0.1 .

To solve the model we need to fix the value of $u$, the hours spent by agents in the final sector. We fix this value at 0.5 assuming that individuals spend about 50 percent of their time working in the sector of consumables and investment goods. And because in this model time, net of leisure, is equal to 1 , the other $50 \%$ is spent in the accumulation of human capital ( see Devereux and Love ([1994], p. 521 for a similar assumption).

\subsection{Results}

Given the parameter values above, we solve the model numerically and the results are reported in Table 3 . We report both the values for the balanced growth rates and for the physical to human capital ratio, while the $\mathrm{C} / \mathrm{K}$ ratio and human capital are described by plotting their steady state values in Figures: 5 and 6.

The main finding is that an increase in taxation increases the balanced growth rate of the economy, thus lending support to the first model. For the other variables, the $\mathrm{K} / \mathrm{H}$ ratio is always decreasing in the tax rate, the $\mathrm{C} / \mathrm{K}$ ratio is increasing, because of the increase in the growth rates, and human capital is decreasing for low tax rates and begins to increase for tax rates higher than $30 \%$.

\footnotetext{
${ }^{5}$ See in particular Heckman (1976).
} 
TABLE 3

\section{VALUES OF THE STEADY STATE VARIABLES IN THE MODEL WITH PUBLIC AND PRIVATE INVESTMENT IN HUMAN CAPITAL}

Parameter values for the base case $\{B=0.38, \alpha=0.35, \rho=0.04 \delta=0.1, \beta=0.45, u$

$$
=0.50\}
$$

\begin{tabular}{cccc}
\hline $\begin{array}{c}\text { Tax rate } \\
\tau\end{array}$ & $\begin{array}{c}\text { Growth rate } \\
\boldsymbol{\gamma}\end{array}$ & $\begin{array}{c}\text { Percentage change in } \\
\text { growth rates }: \Delta \boldsymbol{\gamma}\end{array}$ & $\begin{array}{c}\text { Physical to human capital } \\
\text { ratio }: \mathbf{k}\end{array}$ \\
\hline 0.10 & 0.000421 & --- & 1.732934 \\
0.15 & 0.01589 & +1.54 & 1.351325 \\
0.20 & $* 0.02770$ & +1.18 & 1.100142 \\
0.25 & 0.03716 & +0.99 & 0.915493 \\
0.30 & 0.04491 & +0.77 & 0.077082 \\
0.35 & 0.05130 & +0.64 & 0.652724 \\
0.40 & 0.05656 & +0.53 & 0.553540 \\
0.45 & 0.06080 & +0.42 & 0.468535 \\
0.50 & 0.06411 & +0.33 & 0.394590 \\
0.55 & 0.06651 & +0.24 & 0.329560 \\
0.60 & 0.06800 & +0.14 & 0.271926 \\
0.65 & 0.06851 & +0.05 & 0.220586 \\
0.70 & 0.06795 & -0.06 & 0.174739 \\
0.75 & 0.06611 & -0.18 & 0.133812 \\
0.80 & 0.06267 & -0.34 & 0.097422
\end{tabular}

It is clear from the values in Table 3 that starting from a value of the growth rate of $2.7 \%$ when the tax rate is $20 \%$, an increase in taxation increases the growth rate. For instance, an increase in $\tau$ from 20 to $30 \%$, increase the growth rate by $1.72 \%$ and a further increase in that rate from 30 to $40 \%$ would increase the growth rate by $1.16 \%$. The pattern is shown in Table 3. The growth rate is increasing in the tax rate up to a rate of taxation of 65 percent.

Figure 3
Figure 4
Figure 5
Figure 6

\subsection{Sensitivity Analysis}

We report the values of the steady state growth rates when we change some parameter values. These parameters are changed one at a time leaving all the others equal to the base case. The results are displayed in Table 4. Then we compare these values with the base case and the percentage differences with respect to the latter are reported in Table 5 . 
TABLE 4

STEADY STATE GROWTH RATES AFTER CHANGING THE SET OF PARAMETER VALUES: $\underline{B, \alpha \text { and } \beta}$

\begin{tabular}{cccc}
\hline Tax rate & $\mathrm{B}=0.6$ & $\alpha=0.50$ & $\beta=0.65$ \\
$\tau$ & & & \\
\hline 0.20 & 0.0873 & 0.05034 & 0.01103 \\
0.25 & 0.1010 & 0.05845 & 0.02235 \\
0.30 & 0.1122 & 0.06451 & 0.03182 \\
0.35 & 0.1214 & 0.06891 & 0.03976 \\
0.40 & 0.1290 & 0.07192 & 0.04636 \\
0.45 & 0.1352 & 0.07367 & 0.05174 \\
0.50 & 0.1400 & 0.07425 & 0.05597 \\
0.55 & 0.1434 & 0.07367 & 0.05906 \\
0.60 & 0.1456 & 0.07192 & 0.06098 \\
0.65 & 0.1455 & 0.06891 & 0.06164 \\
0.70 & 0.1454 & 0.06451 & 0.06092 \\
0.75 & 0.1429 & & 0.05855 \\
0.80 & & & 0.05413 \\
\hline
\end{tabular}

Note: The missing values are unimportant for the pattern of the growth rate. We stop at the value of the tax rate at which the growth rate begins to decrease. It seems obvious therefore that for higher tax rates we are in the decreasing segment as figure 3 shows.

\section{TABLE 5}

PERCENTAGE CHANGE OF GROWTH RATES WITH RESPECT TO THE BASE CASE

\begin{tabular}{cccc}
\hline Tax rate & $\mathrm{B}=0.6$ & $\alpha=0.5$ & $\beta=0.65$ \\
$\tau$ & & & \\
\hline 0.20 & +5.96 & +2.26 & -1.66 \\
0.25 & +6.38 & +2.12 & -1.48 \\
0.30 & +6.72 & +1.96 & -1.30 \\
0.35 & +7.01 & +1.76 & -1.15 \\
0.40 & +7.24 & +1.53 & -1.02 \\
0.45 & +7.44 & +1.28 & -0.90 \\
0.50 & +7.58 & +1.01 & -1.05 \\
0.55 & +7.68 & +0.71 & -0.81 \\
0.60 & +7.76 & +0.39 & -0.66 \\
0.65 & +7.77 & +0.04 & -0.70 \\
0.70 & +7.76 & +0.03 & -0.68 \\
0.75 & +7.68 & & \\
0.80 & +7.52 & & \\
\hline
\end{tabular}

Notes: Figures in the Table refer to percentage changes. The sensitivity analysis is conducted by comparing the steady state growth rate in the base case and the growth rate obtained after change in the parameter in each column.

\section{Discussion of the Results}

As it is well known, Barro (1990) and Barro and Sala-i-Martin (1992), who initiated the literature on government policy and endogenous growth, pointed out that income taxation can have, for small sizes of government, a positive effect on growth when proceeds from taxation are used in a productive way. There are cases, such as 
congestion in the use of public goods in which to levy a proportional tax on output may be Pareto improving. Even though education does not create congestion, such as in the provision of other public goods, our findings are that taxation on output may lead to faster growth for sizes of government which are much higher than that in Barro's (1990) model or in other models. The intuition of our result is very simple. When government spending is endogenous and productive in a more direct way, such as public spending on education, it is not counterfactual to find that the optimal tax rate is not zero in the long run or very small. Obviously this result is in contrast with Ramsey's solution in models in which government spending is either exogenous or unproductive.

We already stressed the possibility of similar positive effects in other models. Jones Manuelli and Rossi (1993), for example, showed that the optimal limiting tax could not go to zero but their solution is for a small positive income tax. Devereux and Love (1995) show a positive effect on growth from lump sum taxes but a negative one from distortionary taxes. Other models in which the impact of taxation is negative utilize models in which leisure is home production with physical capital as an input. Obviously in this kind of models distortions will be higher (Roubini and Milesi Ferretti [1994]) than those considered in this paper. The introduction of home production for leisure means that when other sectors are taxed, agents prefer home production instead of market goods distorting, as a result, the allocation of factors in the economy. In Corsetti and Roubini's (1996) paper, positive optimal tax rates depend crucially on which factor (physical or human capital) appropriates the rents from externalities of productive government spending, which is modeled as a complementary factor in the production of final output as in Barro (1990). Most empirical evidence shows that taxes in all countries are much higher than those calculated in these theoretical models and have never seemed to be an obstacle to growth.

In this simple model, in which government spending enters as an input in the human capital accumulation equation, the results are consistent with the evidence. Several computations have been made and the conclusions seem to be robust. The sensitivity analysis shows no change in the relationship between tax rates and growth for a wide range of parameter values. Computations in tables 4 and 5 confirm the qualitative nature of the results.

\section{Conclusions}

This paper adds to the growing literature on dynamic fiscal policy exploring the effects of a combination of government spending and taxation in an endogenous growth set-up.

We have presented a convex model of endogenous growth in which two different assumptions about human capital technology have been made. The first one in which the process of human capital accumulation is driven only by the government. The second one includes time by individuals together with public spending as inputs in the process of formation of human capital. We show that output taxation may raise growth rates when their proceeds are used to supply education. The intuition is clear. Government spending contributes to human capital accumulation in a model in which the latter is the engine of growth. The increase in growth, will increase the revenues from taxation and hence human capital accumulation again. That government spending and taxation may have a positive effect on growth is now becoming a field of research 
by some authors who see it not as a perverse result but as an important policy implication. Obviously for very high tax rates the distortions in the allocation of resources and in the physical to human capital ratio would prevail and the growth rate begins to decrease. This, together with other inefficiency linked to provision of public goods as stressed by Barro (1990) and Barro and Sala-i- Martin (1992), may explain the non-monotonic relationship between growth and tax rates.

Besides the positive impact of a combination of government spending and taxation on growth, the most striking result is the entity of the tax rate which maximizes growth which is comprised, in both models presented, between 65 and $70 \%$ for plausible values of the parameters used. It would suggest that the structure of government spending may be more important than its level (government size).

An important topic for future research would be to consider empirically if countries with different rates of education provided by the government are associated with relatively high growth income rates. The existence of such correlation, if found, would be a clear sign that the prediction of this model is not uncorrect.

\section{References}

Auerbach, A. and Kotlikoff, L.J. (1987). Dynamic Fiscal Policy, Cambridge, Cambridge University Press

Barro, R. (1990). Government Expenditure in a Simple Model of Endogenous Growth, Journal of Political Economy, 98, S103-S125

Barro, R and Sala-i-Martin, X (1992). Public Finance in Models of Economic Growth, Review of Economic Studies, 59, 645-61

Barro, R. and Sala-i-Martin, X. (1995). Economic Growth, New York, McGraw-Hill

Capolupo, R. (1996), Endogenous Growth with Public Provision of Education, Working Paper No. 96/38, University of York

Chamley, C. (1986). Optimal Taxation of Capital Income in General Equilibrium with Infinite Lives, Econometrica, 54, 607-22

Corsetti, G. and Roubini, N. (1996), Optimal Government Spending and Taxation in Endogenous Growth Models, W.P, CEPR april (preliminary draft)

Devereux, M.B., and Love, D.R.F. (1994), The Effects of Factor Taxation in a Two Sector Model of Endogenous Growth, Canadian Journal of Economics, XXVII, n.3,509-536

Devereux, M.B., and Love, D.R.F. (1995),Dynamic Effects of Government Spending Policies in a Two Sector Endogenous Growth Model, Journal of Money, Credit and Banking, 27, February, 233-256

Easterly, W. (1993). How Much Distortions Affect Growth?, Journal of Monetary Economics, 32, $187-212$

Easterly W., and Rebelo S.,(1994)Fiscal Policy and Economic Growth, CEPR Discussion Paper n. 885

Glomm, G. and Ravikumar, B. (1992). Public versus Private Investment in Human Capital: Endogenous Growth and Income Inequality, Journal of Political Economy, 100, 818-33

Hall, R. (1988), Intwertemporal substitution in Consumption, Journal of Political Economy, 96, april, 339-357

Heckman, J. (1976). A Life Cycle Model of Earning, Learning and Consumption, Journal of Political Economy, 84, august, pt 2 S11-S44

Jones, L. Manuelli, R. and Rossi, P. (1993). Optimal Taxation in Models of Endogenous Growth, Journal of Political Economy, 101, 485-517

Judd, K.L. (1987). The Welfare Cost of Factor Taxation in a Perfect Foresight Model, Journal of Political Economy, 95, 617-709

King, R. G. and Rebelo, S. (1990). Public policy and Endogenous Growth. Developing Neoclassical Implication, Journal of Political Economy, 98, S126-S150 
Lucas, R. (1988). On the Mechanics of Economic Development, Journal of Monetary Economics, 22, 3-42

Lucas, R (1990). Supply Side economics: An Analytical Review, Oxford Economic Papers,42, 293 316

Maddison, A. (1991), Dynamic Forces in Capitalist Development, Oxford, OUP

Mulligan, C.B. and Sala-i-Martin, X. (1993). Transitional Dynamics in Two Sector Models of Endogenous Growth, Quarterly Journal of Economics, 108, 739-73

Pecorino, P.,(1993) Tax Structure and Growth in a Model with Human Capital, Journal of public economics, 52, 251-271,

Ram Rati, (1986) Government Size and economic Growth: A New Framework and some Evidence from Cross Section and time series data, American Economic Review, march 1986, 500-521

Rebelo, S (1991). Long Run Policy Analysis and Long Run Growth, Journal of Political Economy, $99,500-521$

Roubini, N. and Milesi-Ferretti, G.M. (1994). Taxation and Long Run Growth in Open Economies, NBER Working Papers, n. 4481, october

Roubini, N. and Milesi-Ferretti, G.M. (1995) Growth effects of Income and consumption Taxes: Positive and Normative Analysis, NBER Working Paper, n. 5317, October.

Stokey, N.L. and Rebelo, S. (1995), Growth Effects of Flat Rate Taxes, Journal of Political Economy, 103, 519-50

Trostel, P. (1993). The Effects of Taxation on Human Capital, Journal of Political Economy, 101, 327-49.

Turnovsky, S.(1996), Fiscal Policy, Growth and Macroeconomic Performance in a small Open Economy, Journal of International Economics,

Uhlig, H. and Yanagawa, N (1996). Increasing the Capital Income Tax may lead to Faster Growth, European Economic Review, 40, november, 1521-1540 